\title{
Failure Analysis of Automatic Access Pedestrian Gate Turnstile using SolidWorks Simulation Model
}

\author{
${ }^{1}$ E.K. Orhorhoro, ${ }^{2}$ O. Erhinyodavwe and ${ }^{3}$ A.E. Ikpe \\ ${ }^{1}$ Department of Mechanical Engineering, Delta Sate Polytechnic, Otefe-Oghara, Nigeria \\ ${ }^{2,3}$ Department of Mechanical Engineering, University of Benin, Nigeria \\ ${ }^{1}$ kelecom@yahoo.com
}

\begin{abstract}
This research work is focused on the failure analysis of Automatic Access Pedestrian Gate Turnstile using SolidWorks Simulation Model. Failure analysis was carried out on both static and dynamic failure of the system putting into consideration the yield stress, resultant displacement, failure cycle, percentage damage, maximum strain and most importantly factor of safety. The results of Von Mises stress analysis showed that a maximum value of $5.77 \mathrm{Mpa}$ yield strength was obtained. A displacement of $0.257737 \mathrm{~m}$ and a strain value of $2.03989 \times 10^{-5}$ were obtained respectively. The fatigue simulation damage factor was not up to $100 \%$ though is up to $50 \%$. At the endurance limit or fatigue limit, the SN curve flattens at $10^{6}$ cycle. A safety of 61 was recorded with the system which is above 1 , thus the system is safe and efficient and can be used for security check.
\end{abstract}

Index Terms- Security, Automatic Access Pedestrian Gate Turnstile, SolidWorks Simulation Model, Failure Analysis

\section{INTRODUCTION}

Nigeria has consistently ranked low in the Global Peace Index (Azazi, 2011), signifying a worsened state of insecurity in the country. Hence, Adagba et al [1], Uhunmwuangho and Aluforo [2] are of the opinion that the efforts of government have not yield enough positive result. Security as an essential concept is commonly associated with the alleviation of threats to cherished values, especially the survival of individuals, groups or objects in the near future [3]. As the world is going through a period of technological advancement, the need arises for automated system which can help in security check and the same time operate with little or no human interference. One of such system is the automatic access control system (automated turnstile). Access control system is designed for area where need for security is crucial especially in the institutions. It protects human life, property, information and the same time provides safe and comfortable environment by limiting unnecessary access to essential areas such as offices, building, schools, factories etc. $[4,5,6]$. It is a biometric access control system that work by identifying the smart card, and in so doing, it prevents any possible danger or interference from the outside and thereby providing safety in any environment $[7,8]$.

Any mechanical system is expected to fail with time. This makes it necessary to carry out failure analysis in design stage and after fabrication/construction. The failure mode could be a static or dynamic failure depending on the operating system. Static failure could be as a results of point load while dynamic failure might be as the consequence of fatigue failure resulting from continuous cyclic stress. Analysis of failure in a mechanical system is a difficult task especially if it is done manually, thus the need for CAD analysis such as SolidWorks Simulation. The Computer-Aided-Design (CAD) is a powerful technology tool that enables researchers to simulate, identify and address critical design failure. In this research work, SolidWorks Simulation Model will be used to investigate all possible failures in the frame assembly of the Automatic Access Pedestrian Gate Turnstile. Both static and dynamic failure analysis will be 
carried out to see if the design Automatic Access Pedestrian Gate Turnstile is good enough to be use as a means of security check.

\section{METHODOLOGY}

SolidWorks is a solid modeler that make use of parametric (i.e. constraints whose values can determine the geometry of the model) features (i.e. building blocks of the part) base approach to create models. Both static and fatigue failure will be analyzed using SolidWorks Simulation model. The fatigue analysis will examine how continuous passages of people through the Automatic Access Pedestrian Gate Turnstile will cause failure. This will allow for proper design for strength and design for life of the system. Figure 2.1 shows the complete model of the simulated turnstile frame assembly, while Table 2.1 shows the solid bodies used for the analysis. In this research work, both dynamic and static failure will be analyzed. For the latter, Von Mises failure criteria will be applied. According to Von Mises failure criteria, yielding of a ductile material commences when the second deviatoric stress invariants reaches a critical value. In other words, failure will occur when the energy of distortion reaches the same energy for yield/failure in uniaxial tension. For the former, fatigue failure of the material will be analyzed and this will be achieved with the SN curve. The SN curve will be used to analyzed failure caused by fatigue. An SN curve defines the number of cycles to failure, when a material is repeatedly cycled through a given stress range.

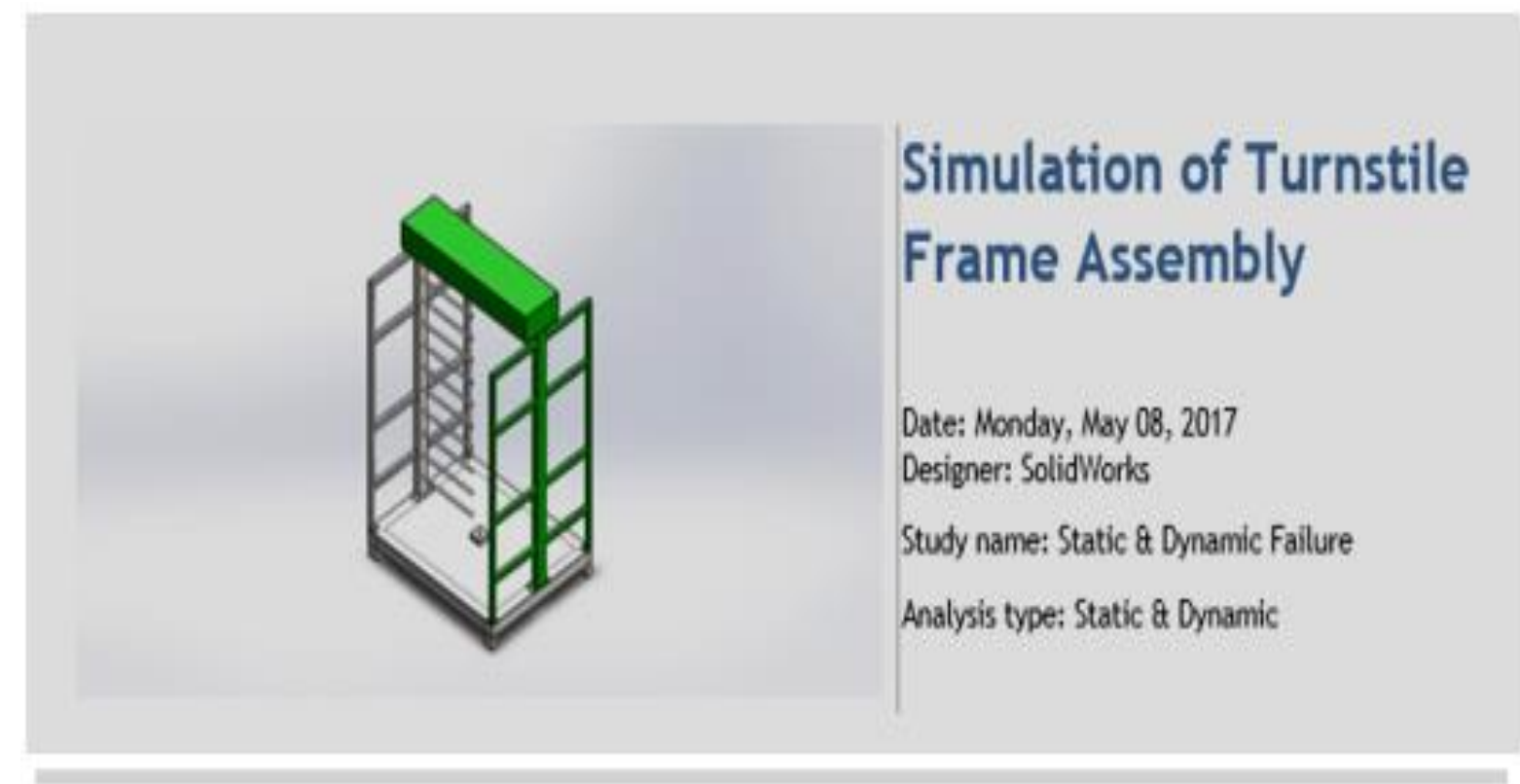

Figure 1: Complete model 
Table 2.1: Solid bodies

\begin{tabular}{|c|c|c|}
\hline $\begin{array}{c}\text { Document Name and } \\
\text { Reference }\end{array}$ & Treated As & Wolumetric Properties \\
\hline Steel portion & Solid Body & 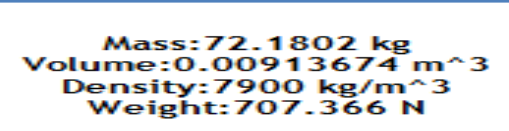 \\
\hline Boss-Extrudes & Solid Body & 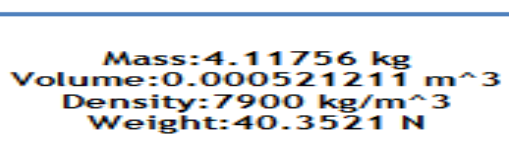 \\
\hline Wooden Portion & Solid Body & $\begin{array}{c}\text { Mass: } 73.7084 \mathrm{~kg}^{2} \\
\text { Volume:0.00933017 } \mathrm{m}^{3} \\
\text { Density: } 7900 . \mathrm{kg}^{3} \mathrm{~m}^{3} \\
\text { Weight: } 722.342 \mathrm{~N}^{3}\end{array}$ \\
\hline
\end{tabular}

Table 2.2 shows the study properties and material properties is shown in Table 2.3. In this research work, static and dynamic failure are the focus point. Under fatigue stress, mean stress correction with reference to Goodman line will be address. All failures cause by fatigue will be interpreted with SN curve. On static failure, the yield strength of the material will be look into putting thermal effect and every other factors into consideration. Von Mises criteria will be used for confirmation of prospective failure.

Table 2.2: Study properties

\begin{tabular}{l}
\hline Study name \\
\hline Analysis type \\
\hline Mesh type \\
Thermat Eftect: \\
Thermal option \\
Zero strain temperature \\
Include fluid pressure effects from SolidWorks \\
Flow Simulation \\
\hline Solvertype \\
\hline Inplane Effect: \\
\hline Sott Spring: \\
\hline Inertial Reliet: \\
\hline Incompatiblebonding options \\
\hline Large displacement \\
\hline Compute tree body torces \\
\hline Friction \\
\hline Use Adaptive Method: \\
\hline
\end{tabular}

\begin{tabular}{l} 
Static 1 \\
Static \\
Solid Mesh \\
On \\
Includetemperature loads \\
298 Kelvin \\
Off \\
FFEPtus \\
Orf \\
Off \\
Off \\
Automatic \\
Off \\
On \\
Off \\
Off \\
\hline
\end{tabular}

\begin{tabular}{|l|l|}
\hline Study name & Fatigue 1 \\
\hline Analysis type & Fatigue(Constant Amptitude) \\
\hline Event Interaction & Random \\
\hline Computing alternating stress using & Equivalent stress (von Mises) \\
\hline Shell face & Top Face \\
\hline Mean stress correction & Goodman \\
\hline Fatigue strength reduction factor & 1 \\
\hline Infinite Iffe & Off \\
\hline Result folder & $\begin{array}{l}\text { SolidWorks document (C;USersiERHINYODAVWE } \\
\text { ONORIODEDocumentsiUniversity of BeniniPG } \\
\text { StudentsiTurnstile Project Assembly) }\end{array}$ \\
\hline
\end{tabular}


The materials used for the design of the turnstile frame work has the properties shown below. The material has a Poisson's ratio of 0.29 . The yield strength of the material is $3.51571 \mathrm{e}+008 \mathrm{~N} / \mathrm{m}^{\wedge} 2$, while the tensile strength is $4.20507 \mathrm{e}+008 \mathrm{~N} / \mathrm{m}^{\wedge} 2$.

Name: $\quad$ AISI 1020

Model type: $\quad$ Linear Elastic Isotropic

Default failure criterion: Max von Mises Stress

Yield strength: $\quad 3.51571 \mathrm{e}+008 \mathrm{~N} / \mathrm{m}^{\wedge} 2$

Tensile strength: $\quad 4.20507 \mathrm{e}+008 \mathrm{~N} / \mathrm{m}^{\wedge} 2$

Elastic modulus: $\quad 2 \mathrm{e}+011 \mathrm{~N} / \mathrm{m}^{\wedge} 2$

Poisson's ratio: $\quad 0.29$

Mass density: $\quad 7900 \mathrm{~kg} / \mathrm{m}^{\wedge} 3$

Shear modulus: $\quad 7.7 \mathrm{e}+010 \mathrm{~N} / \mathrm{m}^{\wedge} 2$

Thermal expansion $\quad 1.5 \mathrm{e}-005 /$ Kelvin

coefficient:

Table 2.3 shows loads and fixtures information while Table 2.4 shows contact information. In Table 2.3, there are three component of force. These forces are in the $\mathrm{X}, \mathrm{Y}$, and $\mathrm{Z}$ axis. The resultants forces and moment of the three reactant component forces will determine, and this will help to predict possible failure.

Table 2.3: Loads and fixtures information

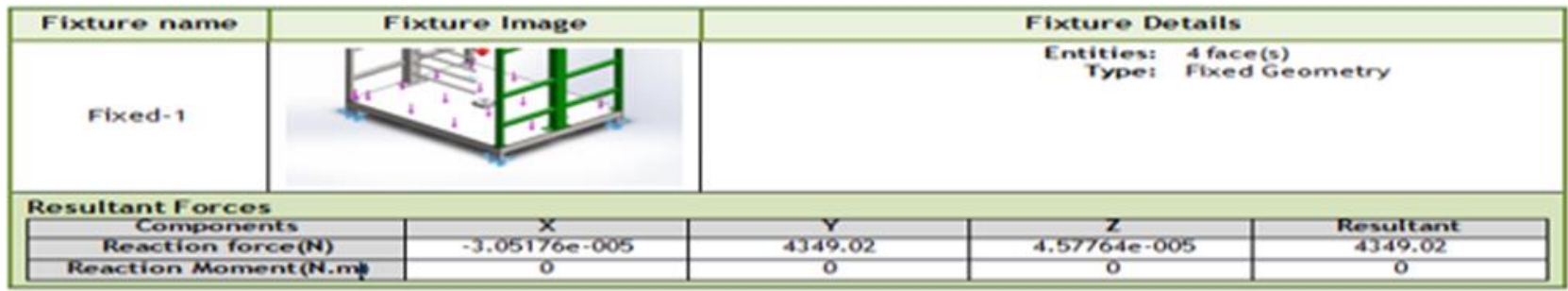

\begin{tabular}{|c|c|c|c|}
\hline Load name & Load Image & \multicolumn{2}{|c|}{ Load Details } \\
\hline & & $\begin{array}{r}\text { Reference: } \\
\text { Valunes: } \\
\text { Units: }\end{array}$ & $\begin{array}{l}\text { Top Plane } \\
\text { o' } 0.8 .81\end{array}$ \\
\hline Force-1 & & $\begin{array}{r}\text { Entities: } \\
\text { Type: } \\
\text { value: } \\
\text { Phase Angle: } \\
\text { Units: }\end{array}$ & $\begin{array}{l}\text { 1 face(s) } \\
\text { Apply normal force } \\
1177.2 \mathrm{~N} \\
\text { O'es } \\
\text { Des }\end{array}$ \\
\hline Force-2 & & $\begin{array}{r}\text { Entities: } \\
\text { Type: } \\
\text { Value: } \\
\text { Phase Angle: } \\
\text { Units: }\end{array}$ & $\begin{array}{l}1 \text { face(s) } \\
\text { Apply normal force } \\
190.2 \mathrm{~N} \\
\text { Oes }\end{array}$ \\
\hline
\end{tabular}

As shown in Table 2.4, for contact set 1, there are two faces entities, one component, and an option of compatible mesh for global contact. 
Table 2.4: Contact Information

\begin{tabular}{|c|c|}
\hline Contact & Contact Properties \\
\hline Contact Set-1 & $\begin{array}{r}\text { Type: No Penetration } \\
\text { contact pair } \\
\text { Entities: } 2 \text { face(s) } \\
\text { Advanced: Node to surface }\end{array}$ \\
\hline Global Contact & Type: Bonded \\
& Components: 1 component(s) \\
& Options: Compatible mesh \\
\hline
\end{tabular}

The SolidWorks mesh information shown that curvature based mesh was used with Jacobian four points, $182.811 \mathrm{~mm}$ maximum element sizes, and $36.5622 \mathrm{~mm}$ minimum element size. The mesh quality is high, and there was no remesh failed parts with incompatible mesh. Below is the detail summary of the mesh information.

Total Nodes-80983

Total Elements-19760

Maximum Aspect Ratio-536.61

$\%$ of elements with Aspect Ratio $<3-20.3$

$\%$ of elements with Aspect Ratio > 10-26

$\%$ of distorted elements(Jacobian)- 0

\section{RESULTS AND DISCUSSION}

\section{STATIC FAILURE}

The reaction force in the $\mathrm{X}$-components is $-3.05176 \mathrm{e}-005 \mathrm{~N}$, while the reaction force in the $\mathrm{Y}$ and $\mathrm{Z}$ components are $4349.02 \mathrm{~N}$, and $4.57764 \mathrm{e}-005 \mathrm{~N}$ respectively. The resultant force of the three components is $4349.02 \mathrm{~N}$. However, the reaction moment in Newton meter for each of the components is zero, this means the resultant moment is zero.

Table 3.1: Resultant forces

Reaction Forces

\begin{tabular}{|c|c|c|c|c|c|}
\hline Selection set & Units & Sum X & Sum Y & Sum Z & Resultant \\
\hline Entare Model & $N$ & $-3.031 / 0 e-U u b$ & 4349.02 & $4.5 / 104 e-$-US & 4349.02 \\
\hline \multicolumn{6}{|c|}{ Reaction Moments } \\
\hline Selection set & Units & Sum X & Sum Y & Sum Z & Resultant \\
\hline Enture Model & N.m & u & U & $\mathrm{U}$ & $\mathrm{U}$ \\
\hline
\end{tabular}

The Von-Mises stress analysis results shown that a maximum yield stress of 5.77 Mpa was obtained (Figure 1). A maximum value of 5.77Mpa yield strength will not cause failure. This is because a failure from the analysis will only occur if a yield stress is minimal compared to the yield strength $351 \mathrm{Mpa}$ that causes failure. 
INTERNATIONAL JOURNAL OF ENGINEERING TECHNOLOGY AND SCIENCES

(IJETS) Vol.8 (1) Dec 2017 DOI: http://dx.doi.org/10.15282/ijets.8.2017.1.3.1078

\begin{tabular}{|c|c|c|c|}
\hline Name & Type & Min & $\operatorname{Max}$ \\
\hline Stress1 & VON: von Mises Stress & $\begin{array}{l}0 \mathrm{~N} / \mathrm{m}^{\wedge} 2 \\
\text { Node: } 32223\end{array}$ & $\begin{array}{l}5.76956 \mathrm{e}+006 \mathrm{~N} / \mathrm{m}^{\wedge} 2 \\
\text { Node: } 897\end{array}$ \\
\hline 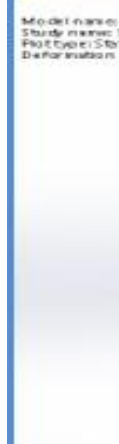 & & & 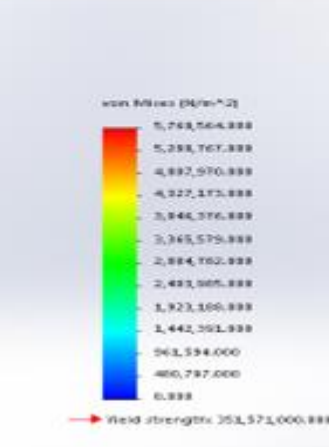 \\
\hline
\end{tabular}

Figure 2: Von- Mises Stress Analysis

The resultant displacement results obtained was $0.257735 \mathrm{~mm}$ (Figure 2). The displacement of $0.257735 \mathrm{~mm}$ cause by the effect of the load is small compared to the thickness of the frame support. Therefore, no meaningful failure will result from that.

\begin{tabular}{|c|c|c|c|}
\hline Name & 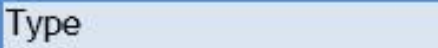 & Min & $\operatorname{Max}$ \\
\hline Displacement1 & URES: Resultant Displacement & $\begin{array}{l}0 \mathrm{~mm} \\
\text { Node: } 35\end{array}$ & $\begin{array}{l}0.257737 \mathrm{~mm} \\
\text { Node: } 10580\end{array}$ \\
\hline 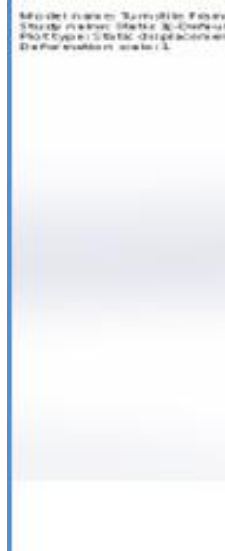 & tile Frame Asse & nt-Dis & 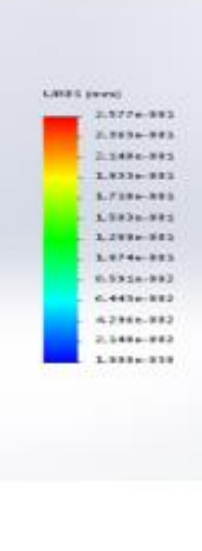 \\
\hline
\end{tabular}

Figure 3: Resultant displacement

From the strain SolidWorks Simulation analysis, a strain value of $2.03989 \times 10^{-5}$ was obtained and this is small enough not to cause failure (Figure 3). 
INTERNATIONAL JOURNAL OF ENGINEERING TECHNOLOGY AND SCIENCES

(IJETS) Vol.8 (1) Dec 2017 DOI: http://dx.doi.org/10.15282/ijets.8.2017.1.3.1078

\begin{tabular}{|l|l|l|l|}
\hline Name & Type & Max & $\begin{array}{l}2.03989 \mathrm{e}-005 \\
\text { Element: } 1268\end{array}$ \\
\hline Strain1 & ESTRN: Equivalent Strain & $\begin{array}{l}6.19096 \mathrm{e}-009 \\
\text { Element: } 10391\end{array}$ \\
\hline & & \\
\hline
\end{tabular}

Figure 4: Strain Analysis

\section{FATIQUE FAILURE}

The fatigue simulation damage factor is not up to $100 \%$ though is up to $50 \%$ (Figure 4), therefore, the system is efficient. The system will be unsafe if the damage factor is $100 \%$ and above.

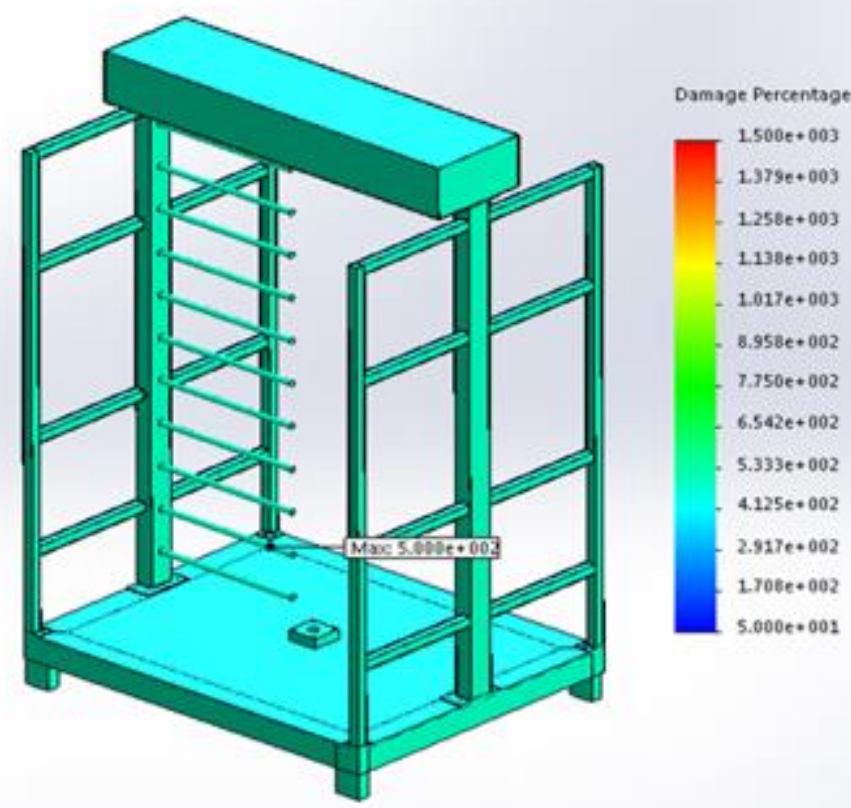

Figure 5: Damage percentage

From the results obtained with fatigue failure analysis (Figure 5), a maximum life cycle of $10^{6}$ was recorded with the system. This implies that the applied continuous stress to the system will not cause fatigue failure. 
INTERNATIONAL JOURNAL OF ENGINEERING TECHNOLOGY AND SCIENCES

(IJETS) Vol.8 (1) Dec 2017 DOI: http://dx.doi.org/10.15282/ijets.8.2017.1.3.1078

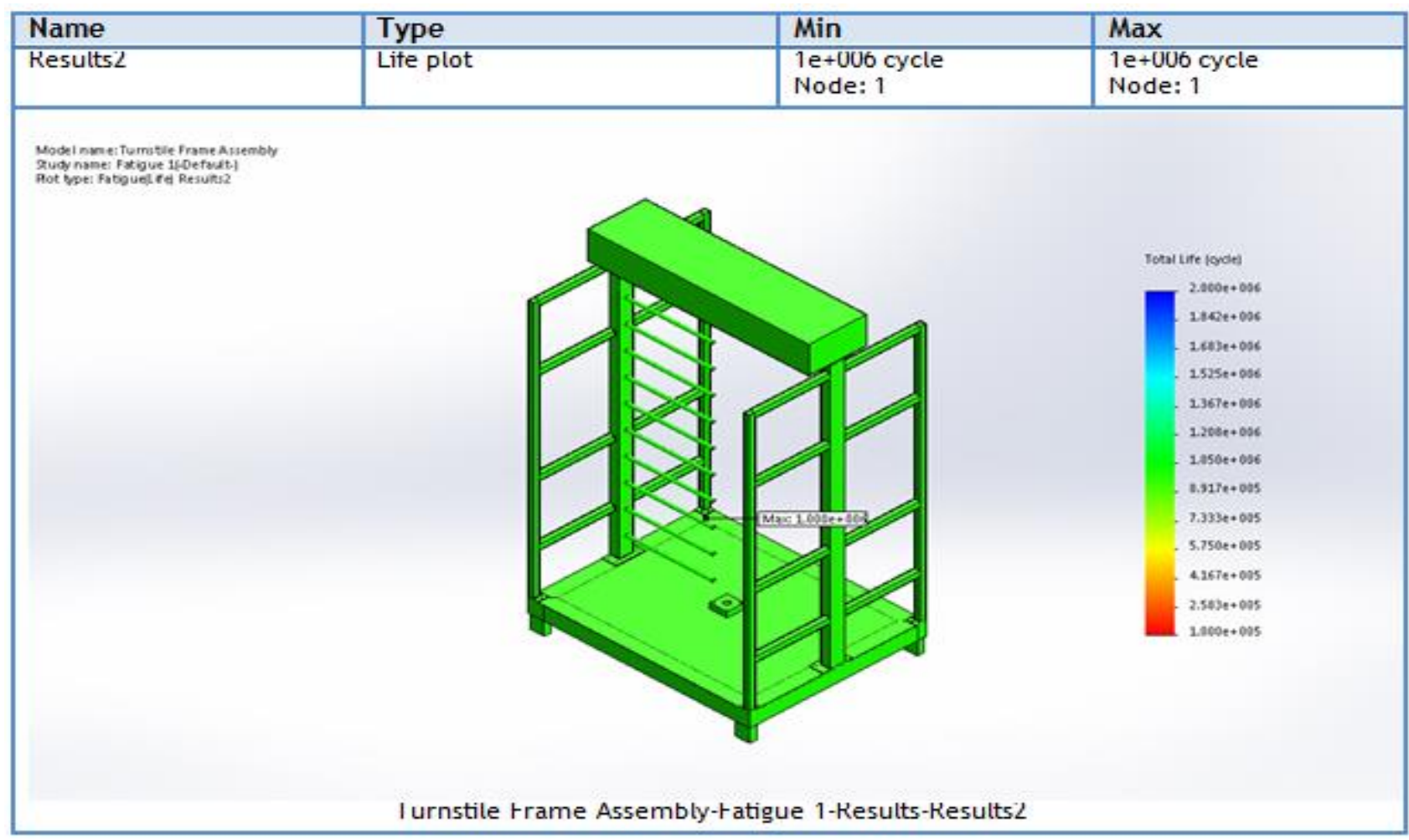

Figure 5: Fatigue Failure Analysis

The SN curve is shown in Figure 6. From the SN curve, the lower the applied stress, the greater the number of cycle to failure. At the endurance limit or fatigue limit, the SN curve flattens at $10^{6}$ cycle. Stress below the fatigue limit can be applied repeatedly in an indefinite number of times without leading to any failure. Thus, the system is safe.

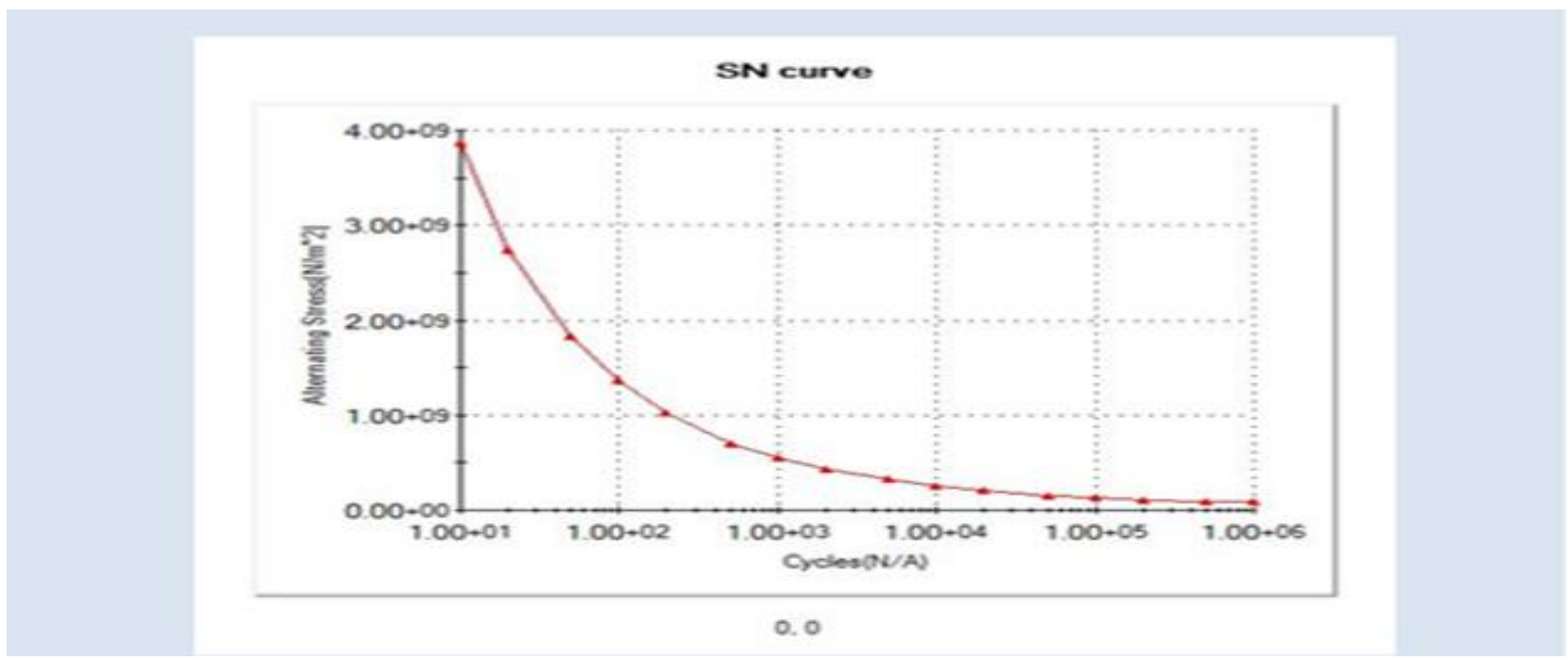

Figure 6: SN Curve

\section{FACTOR OF SAFETY}

The factor of safety is 60.9355 (Figure 7). Since the factor of safety is above one (1), the system is safe and efficient. 


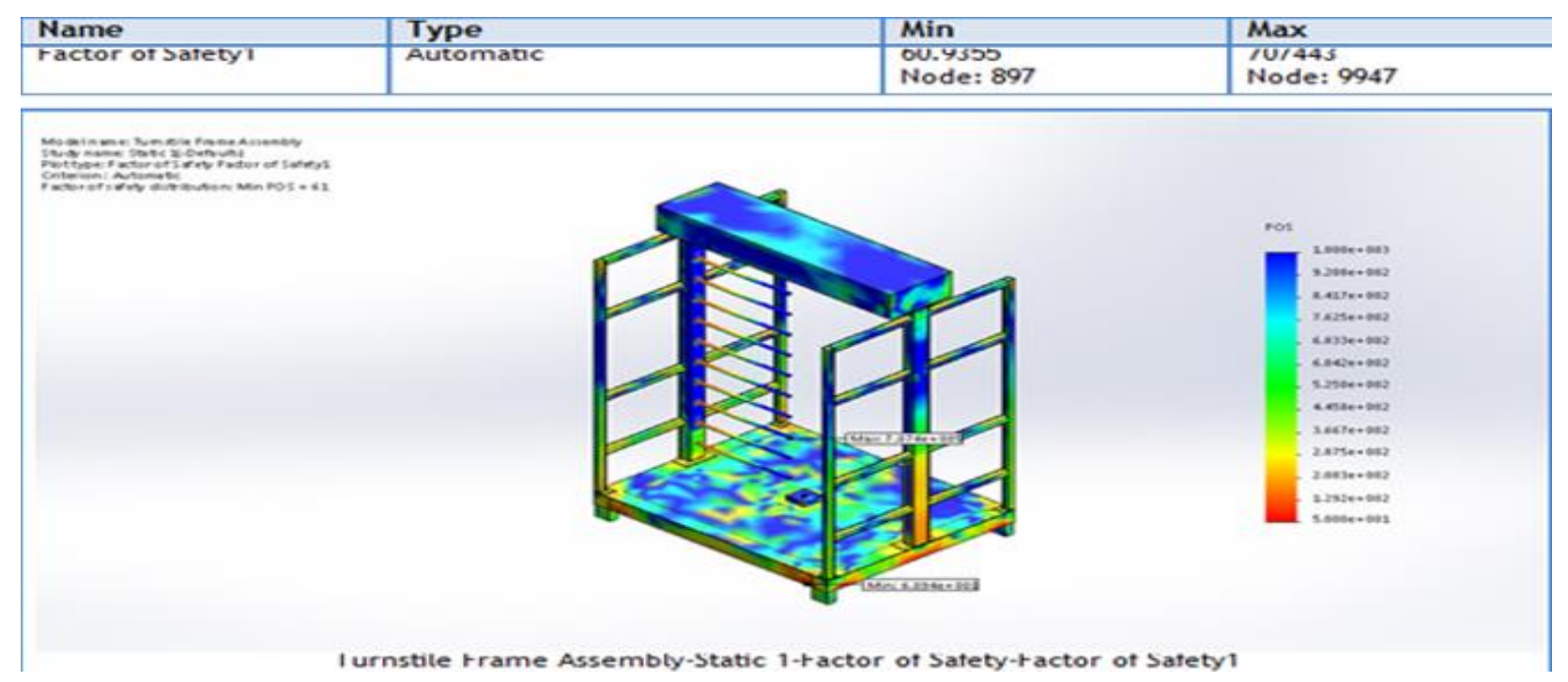

Figure 7: Factor of Safety

\section{CONCLUSIONS}

Due to the problem of insecurity especially in high school, college, banks and hospital, a designed pedestrian gate (turnstile) using an ID card and a card reader was analyzed for failure using SolidWorks Simulation Model. The resultants obtained showed that the system can withstand repeated stress without causing failure and a safety of factor above one prove the system to be safe and efficient. Thus, it can be used for security check.

\section{REFERENCES}

[1] Adagba, O., Ugwu S. C. and Em,' O. I., “Activities of Boko Haram and Insecurity Question in Nigeria", Arabian Journal of Business and Management Review, Vol. 1, No.9, 77-99, 2012

[2] Uhunmwuangho, S.O. and Aluforo, E., "Challenges and Solutions to Ethno-Religious Conflicts in Nigeria, Case Study of the Jos Crises", Journal of Sustainable Development in Africa, Volume 13, No.5, 109-124, 2011

[3] Zungeru, A. M., Edu, U. V. and Garba, A. J., "Design and implementation of a short message service based remote controller", Computer Engineering and Intelligent systems, vol. 3, pp. 106$118,2012$.

[4] Shoewu, 0. and Segun, O. O., "Design and Implementation of a Microcontroller Based Automatic Gate", African Journal of Computing \& ICT, Vol 6. No. 1, pp21-32, 2013

[5] Springer V., Andre R., Reinhardt A. B., and Stephen P., Access control requirements for content management systems. Department of Computer Science, School of IT, University, 2003

[6] Alhaqbani, B. and Fidge, C., Access control requirements for processing electronic health records. In Proceedings of the 2007 international conference on Business process management, BPM'07, pages371-382, 2008 Berlin, Heidelberg

[7] Rostad, L. and Edsberg, O., "A study of access control requirements for healthcare systems based on audit trails from access logs", In Proceedings of the 22nd Annual Computer Security Applications Conference, pages 175-186, Washington, DC, USA. IEEE Computer Society, 2006

[8] Alexander, P., Manuel, H., Florian, S., Christian, S., and Thomas, W. "Usage control enforcement: Present and future", IEEE Security and Privacy, 6:44-53, 2008 